\title{
Engineered Membranes and Transporters for Useful Devices
}

\author{
John Cuppoletti and Danuta H. Malinowska \\ Department of Molecular and Cellular Physiology, \\ University of Cincinnati, \\ Cincinnati $\mathrm{OH}, 45267-0576$
}

USA

\section{Introduction}

Biological membranes consist of lipid bilayers which are permeant to gases and water and some hydrophobic substances, but are impermeant to charged materials such as ions. Biological membranes in cells contain a variety of proteins (ion transporters, ion channels, pumps and other types of pore proteins) to facilitate the transport of ions and other molecules such as glucose and even large molecules such as proteins. The present chapter describes our studies to form bilayers on artificial porous supports and solid supports, and incorporate transporters and ion channels into such artificial membranes in functional form. We were then able to remove ion channels from cells, and place them onto a wide variety of solid and permeant synthetic supports without loss of function. While the above studies involved native ion transport proteins, we also have undertaken studies to modify ion channels to give useful properties. Starting with ion channels of known sequence and crystal structures, these studies outlined the structural basis for functional and regulatory properties. The approaches taken to prepare the engineered composite membranes are generally applicable to the development, design and prediction of properties of a wide variety of materials such as selectively permeable membranes or functionalized thin films with desired chemical, electrical or optical properties. $\mathrm{ClC}-2 \mathrm{Cl}$ - transporting channels, potassium ion channels, and transporters were used for this work. The following major developments have facilitated this phase of the work. First, the primary structure of the ion channels was known from cloning. Second, the X-ray crystal structure and additional NMR structures of a $\mathrm{ClC} \mathrm{Cl}^{-}$channel have been published. Our group was been able to use both the primary structure and the structural information to develop experiments to engineer new properties into the channels. Recent NMR and X-ray crystal structural studies have given important new information regarding the structure of the intracellular C-terminal region of $\mathrm{ClC}-2$, and this information helped to explain the structural basis for our findings that this same region is involved in phosphorylation-dependent regulation of the channel. Dissection and reconstitution of this region has already been carried out, raising our level of confidence that we can exploit this regulatory region further in future studies, such as 
engineering this region to produce ion channel-based sensors which recognize a wide variety ligands by inserting aptamers.

\section{Materials and methods}

\subsection{Formation of bilayers on porous supports}

Bilayers can be formed across a small hole in a hydrophobic support, and ion channel proteins can be incorporated into those membranes $(1,2)$. We expanded this approach to form bilayers on a variety of porous and solid supports containing either single holes in wells, or many holes in a single well (3). Methods were also developed for constructs on solid supported membranes (4). A variety of useful devices were developed using these approaches (please see John Cuppoletti's patents and patent applications at http://patft.uspto.gov/).

\subsection{Formation of lipid bilayers}

For solid supported membrane studies please see (4) and for porous supports, please see (3). In most studies, we used a 3:1 mixture of palmitoyl-oleoyl-phosphatidylserine (POPS) and palmitoyl-oleoyl-phosphatidylethanolamine (POPE) lipids (Avanti Polar Lipids, Birmingham, Ala), $10 \mathrm{mg} / \mathrm{ml}$ and $3.33 \mathrm{mg} / \mathrm{ml}$ in n-decane for formation of the bilayer on porous supports. This preparation appeared to work well for most studies. In the case of the anthrax protective antigen studies, we used 3\% (w/w) 1,2-diphytanoyl-sn-glycero-3phosphocholine in n-decane (Avanti Polar Lipids, Birmingham, Ala). $10 \mu$ of lipid solution was added to the membranes. Buffered salt solution was then added to both sides of the membrane and left for $30 \mathrm{~min}$. A multimeter (Epithelial Volt-ohm-meter, World Precision Instruments, Sarasota, $\mathrm{Fl}$ ) and $\mathrm{Ag} / \mathrm{AgCl}$ reference electrodes were used to measure the resistance across the phospholipid-coated membranes. When gramicidin $\mathrm{D}$ was used to verify that a bilayer was formed (gramicidin is only large enough to cross one leaflet of the bilayer), it was mixed with the lipids to a final concentration of $1 \mu \mathrm{g} / \mathrm{ml}$. $10 \mu \mathrm{l}$ of the lipid/gramicidin mixture was added to the membranes. Alternatively, gramicidin can be added to both sides of the membrane. With gramicidin present in both bilayer leaflets, the resistance of the bilayer decreased, verifying the presence of a lipid bilayer.

\subsection{Measurement of ion currents}

Currents were then measured using an $\mathrm{Ag} / \mathrm{AgCl}$ reference electrode inside the well and a Dri-Ref ${ }^{\mathrm{TM}}$ reference electrode in the outside solution. These were connected to an HS-2A headstage which was connected to a Gene Clamp 500 amplifier (Molecular Devices, Inc. Sunnyvale, California) $(3,4)$. Channel currents were filtered at $60 \mathrm{~Hz}$. Voltages ranging from -80 to $+70 \mathrm{mV}$ were applied in $10-\mathrm{mV}$ increments for $200 \mathrm{~ms}$, and electrical currents were recorded. pCLAMP version 5.5 was used to acquire data and Clampfit 8.0 (Axon Instruments) was used to compare current recordings. Whole cell currents were measured as described for potassium channels $(3,4)$ and chloride channels (5).

\subsection{Types of supports used in these studies}

Solid supported membranes were prepared as described in (4). Commercially available porous membranes were used for most studies. Multiscreen-MIC (10 $\mu \mathrm{m}$ thick) filter plates 
were obtained from Millipore Corporation (Bedford, MA.) that contained inserts with polycarbonate membranes with 3,5 and $8 \mu \mathrm{m}$ pores at the bottom. Micro porous $9 \mu \mathrm{m}$ thick PETE membranes with $3 \mu \mathrm{m}$ pores were obtained from GE Osmonics, Inc. (Minnetonka, $\mathrm{MN})$. Individual wells were excised from the plates for use in these studies. Porous supports were also prepared from various polymers (3). A diagram of the experimental setup is shown in (3).

\section{Results}

Preparation of a device for measurements of the effects of inhibitors on Kv1.5 potassium channels.

Polycarbonate membranes at the base of $0.3 \mathrm{~cm}^{2}$ polystyrene inserts or wells of Millipore Multiscreen-MIC filter plates were used. $10 \mu \mathrm{l}$ of 3:1 POPS: POPE $(40 \mathrm{mg} / \mathrm{ml})$ in n-decane as described above was added to the membranes and left for $30 \mathrm{~min} .100 \mathrm{mM} \mathrm{KCl} / 10 \mathrm{mM}$ HEPES ( $\mathrm{pH}$ 7.4) was then added to both sides of the membrane. An ohmmeter and $\mathrm{Ag} / \mathrm{AgCl}$ reference electrodes were used to measure the resistance across the phospholipidcoated membranes. Solutions containing either potassium or $\mathrm{N}$-methyl glutamine were used to determine ion selectivity. In some cases gramicidin (at a final concentration of $1 \mu \mathrm{g} / \mathrm{ml}$ ) was included in the lipid to demonstrate that a bilayer was obtained (since two head to tail gramicidin molecules is only large enough to form a leak across a bilayer). With gramicidin and potassium solutions, the resistance decreased, indicating that the presence of a bilayer. Membrane vesicles from cells containing Kv1.5 K+ channels or without Kv1.5 K+ channels were prepared as described (3), and incubated with the lipid bilayers across the holes in the membranes. Current across the bilayer was measured as described in the methods. The ion channels in these devices were selective for $\mathrm{K}^{+}$, and were sensitive to a pharmacological compound, an inhibitor of $\mathrm{Kv} 1.5 \mathrm{~K}^{+}$channels, showing that these devices containing reconstituted $\mathrm{Kv} 1.5 \mathrm{~K}^{+}$channels on porous supports were useful for screening of drug candidates (3). (See also US Patent 7833805).

\section{Development of detectors for bacterial pore forming peptides}

Many bacterial pore proteins including $\alpha$-hemolysin from Staphylococcus aureus and the Bacillus anthracis protective antigen 635 (PA63) are secreted and bind to a cell receptor on the host, which then inserts into the membrane. Both proteins have been previously reconstituted, but without receptors (6). A lipid bilayer was formed on a porous support with appropriate receptors (CHO-K1 as a substitute for the normal human receptor) (7), membrane proteins and human red cell membranes. It was then determined whether such membranes could serve as an anthrax detector or $\alpha$-hemolysin detector (see US patent application 20080138839). Lipid bilayers were formed on porous supports as described in the methods. In a control test experiment, ion solutions were then added to the well followed by the addition of varying concentrations of $\alpha$-hemolysin from 0 to about 500 $\mathrm{mg} / \mathrm{ml}$. Once the $\alpha$-hemolysin solution was added, current flow across the membrane as a function of $\alpha$-hemolysin concentration, was measured using standard electrophysiological equipment (Materials and Methods). The experiment was repeated for the same range of $\alpha$-hemolysin concentrations, except that the lipids forming the bilayer membrane were 
mixed with membranes from red blood cells (which include the receptor protein for $\alpha$-hemolysin). Red blood cell membranes were obtained by lysis in $0.15 \mathrm{M} \mathrm{NH}_{4} \mathrm{Cl}, 10 \mathrm{mM}$ $\mathrm{K}_{2} \mathrm{CO}_{3}$, and $0.1 \mathrm{mM}$ EDTA and centrifugation. $1 \mathrm{ml}$ of packed red blood cell membranes was resuspended in the solutions above and added into each well. After $1 \mathrm{hr}$ the ion solutions were added, followed closely by the range of $\alpha$-hemolysin concentrations as used in the control experiment. The current across the membrane was measured as before. We found that $\alpha$-hemolysin inserted into the bilayers with red cell membrane proteins in a concentration dependent manner, and that the red cell membrane proteins shifted the concentration dependence of pore formation to lower concentrations.

To examine whether anthrax proteins could be similarly detected, 3\% (w/w) 1,2diphytanoyl-sn-glycero-3-phosphocholine (7) lipid solution was placed into wells of the porous support. Varying concentrations of protective antigen 635 were added to the bilayer and allowed to incubate for $30 \mathrm{~min}$. Then $100 \mathrm{mM} \mathrm{KCl} / 10 \mathrm{mM} \mathrm{CaCl} / 10 \mathrm{mM}$ Tris, $\mathrm{pH}=7.1-$ 7.4 (neutral salt solution) was added. The plate was then placed into a bath which contained the same neutral salt solution buffer and allowed to incubate for an additional $60 \mathrm{~min}$. Current was measured using pCLAMP software. The experiment was then repeated with $\mathrm{CHO}-\mathrm{K} 1$ cell membrane vesicles added to the lipid bilayer and a dose response to protective antigen 635 was again determined. Interaction of the bilayer and vesicles was allowed to occur over $1 \mathrm{hr}$ and salt solution was then added to the wells. The bilayers were first tested for stability and to see if the bilayers were formed. Then protective antigen 635 was added and allowed to incubate for $1.5 \mathrm{hr}$. Salt solutions were added and the current was again measured at each concentration of protective antigen 635. We found that the concentration of protective antigen 635 which caused a leak current (prevented by the inhibitor tetrabutylammonium chloride) was greatly reduced by the presence of CHO-K1 membranes. This device is thus useful as an anthrax protein detector.

\section{Use of gramicidin as a proton pore for fuel cell membranes}

Gramicidin is a small molecular weight molecule which is available commercially, and which has the property of transporting ions, including protons. We have shown that gramicidin can be easily incorporated into porous membranes using the techniques described above. While having large surface areas of porous membranes is useful for such uses, it appears that high temperatures are required to maintain the integrity of the catalysts which are used in fuel cell membranes. We have found in single channel studies that gramicidin can function at very high temperatures, therefore providing a potential use of these techniques to prepare fuel cell membranes which can function at very high temperatures $\left(95^{\circ} \mathrm{C}\right.$ or greater) (unpublished data).

\section{Solid supported membranes reconstituted with Kv1.5 potassium channels}

There have been several reports of fusion of membrane fragments containing electrogenic ion pumps with solid supported membranes, with a resultant functionally relevant ion current upon concerted activation of the ion pumps $(8,9)$. Building on these studies, we examined whether it would be possible to form solid supported membranes with ion channels (4). However, it was our intent to insert the ion channels directly into a lipid 
bilayer on a solid supported membrane. In these studies, gold coated glass slides with a chromium undercoat and a silver wire added as a ground were reacted with 1-octadecanethiol $(4,8,9)$. Over this layer was placed an epoxy resin which coated most of the surface, but left some surface voids. The expoy resin was then treated with a 3:1 mixture of palmitoyl-oleoyl-phosphatidylserine (POPS) and pamitoyl-oleoylphosphatidylethanolamine (POPE) lipids, $10 \mathrm{mg} / \mathrm{ml}$ and $3.33 \mathrm{mg} / \mathrm{ml}$ in hexane respectively, and used to form a Langmuir monolayer, which was then deposited on the thiol-treated gold slide using the Langmuir-Blodgett technique. Experimental wells of known area were then constructed by placing plastic ring on the surface with silicon grease and sealed with a coating of clear nail polish around the inner edge. Then, membrane vesicles from cells over-expressing Kv1.5 potassium ion channels (or vesicles from cells without Kv1.5 vesicles), were then applied. $\mathrm{K}^{+}$dependent currents were measured when $\mathrm{Kv} 1.5 \mathrm{~K}^{+}$channels were present and these were inhibited by known $\mathrm{Kv} 1.5 \mathrm{~K}^{+}$channel inhibitors (4).

\section{High temperature studies of naturally occurring ion channels}

The question of whether devices containing ion channels can remain active under harsh conditions that may be necessary to use is often raised. Biological transport proteins have potential for use in many biotechnology applications. However, high temperatures or harsh chemical environments could limit their use. In the case of the apical ion channels of gastric parietal cells, these channels are routinely exposed to very low $\mathrm{pH}(\mathrm{pH} 3)$, and are actually activated by low $\mathrm{pH}(1,3)$. We sought to study ion channels which might be active at elevated temperatures. As stated unpublished studies using gramicidin showed $\mathrm{H}^{+}$ transport at temperatures as high as $96^{\circ} \mathrm{C}$. In another study (10) a ClC-like channel from the archeobacter hyperthermophile, Methanococcus jannaschii (mj) which grows at a temperature optimum of $85-90^{\circ} \mathrm{C}$, was cloned from mj genomic DNA. It was ligated into pcDNA3.1/V5His TOPO and stably expressed in HEK293 cells. Cl- currents were studied by patch clamp electrophysiology. ClCmj-expressing HEK293 cells (but not mock transfected cells) exhibited voltage activated $\mathrm{Cl}^{-}$currents which were inhibited by $500 \mu \mathrm{M} \mathrm{CdCl}_{2}$. When membranes were isolated from $\mathrm{ClCmj}$-expressing HEK293 cells and fused to planar lipid bilayers, single $\mathrm{Cl}$ - channels were evident at room temperature $\left(25^{\circ} \mathrm{C}\right)$ and they persisted at elevated temperatures up to at least $96^{\circ} \mathrm{C}$. No channels were evident with membranes from mock transfected HEK293 cells. These studies demonstrated that ion channels from these organisms are functional at elevated temperatures as required for applications in biotechnology.

\section{Manipulation of the properties of ion channels}

Total flow of ions through an ensemble of channels is equal to the number of channels $(\mathrm{N})$, multiplied by the open probability (Po), multiplied by the unit conductance of the channels ( $\gamma)$. Up-regulation of the number of channels by insertion into the membranes being studied, or by increasing the copies of the ion channels are straightforward ways of increasing $\mathrm{N}$. The time spent in the closed or open state can be manipulated by drugs, covalent modification, or by physiological regulation such as phosphorylation or binding of 
endogenous ligands such as fatty acids. The unit conductance of ion channels is generally constant, thereby contributing to the unique signature of the ion channel, although there may be apparent changes to the measured unit conductance when certain drugs are present which modify the open or closed time.

ClC-2 chloride channels are the major focus of study of our laboratory $(1,2,5,11,12)$. Early studies showed that these channels from human and rabbit (in contrast to rat $\mathrm{ClC}-2$ ) were activated by treatments which raised the levels of intracellular cAMP. The rabbit form of ClC-2 was cloned and shown to contain sites which were predicted to be sites for phosphorylation by cAMP dependent protein kinase (PKA) (12). This suggested that ClC-2 was regulated by phosphorylation. The human $\mathrm{ClC}-2$ protein sequence was shown to contain similar sites (13). In order to explore further regulation by protein kinase, we used programs which identified potential phosphorylation sites on the human (and rabbit) $\mathrm{ClC}-2$ protein amino acid sequence, and compared these with those present on the rat $\mathrm{ClC}-2$ protein. Both human and rabbit $\mathrm{ClC}-2$ sequences contained in the C-terminus, two potential phosphorylation sites that were absent from the rat $\mathrm{ClC}-2$ channel. The two sites on the human ClC-2 channel were then probed by site-directed mutagenesis, where the amino acids responsible for accepting the phosphate serine and threonine in the two predicted sites, were changed to alanine. In both cases, the single site mutant channels could be activated by phosphorylation, albeit with slightly different properties (5). However, when both sites were simultaneously changed to alanine, the channel could not be activated by phosphorylation, demonstrating that the two sites were important to regulation of the channel by phosphorylation (5). Moreover, when one of the sites was changed to aspartate, a mimetic of phosphorylation, the channel was constitutively open, and could not be further activated by phosphorylation. This approach has practical implications in generating channels which are constituently active and thus useful for studies of inhibitors of the channel, which is normally inactive in the absence of activators or PKA phosphorylation. This approach can also generate a ClC-2 channel that cannot be activated by cAMP or activators that act through PKA phosphorylation, which would be useful when searching for direct activators of this ion channel.

\section{Covalent chemical modifications of ion channels}

The rabbit and human forms of the $\mathrm{ClC}-2$ chloride channel are also activated by low extracellular $\mathrm{pH}$. Thus the channel is more active at $\mathrm{pH} 3.0$ than at $\mathrm{pH} 7.4$. To identify the charged residues on $\mathrm{ClC}-2$ which lead to activation by low extracellular $\mathrm{pH}$, an analysis of the predicted topology of the channel was first carried out, and a charged region of the channel was identified that was thought to be glycosylated and therefore exposed to the outside of the cell. Site directed mutagenesis and analysis of channels can be very time consuming. An alternative approach was first taken to determine whether acidic amino acids were indeed involved in the $\mathrm{pH}$ activation seen in rabbit $\mathrm{ClC}-2$. We used water soluble carbodiimide to catalyze the amidation of the channel protein (1). The carbodiimide would only access the outer surface of the channel. We found that treatment with the amidation reagents led to activation of the channel to levels similar to that seen with acidic $\mathrm{pH}$. We then carried out site directed mutagenesis of the putative amino acids and showed that changes of a single glutamate to glutamine led to loss of activation by low extracellular $\mathrm{pH}$, 
while other changes did not affect $\mathrm{pH}$ activation. This approach has practical applications in that the channel can be activated constitutively by amidation without the need of low extracellular $\mathrm{pH}$. As one approach the amidation reagents might be used to activate the channel when it is available to the environment such as in the lung or in devices (see US patent 6,159,698).

Other approaches to covalent modification were also carried out. We have studied chloride transport in the stomach for many years in the context of gastric acid secretion. It was known that the gastric $\mathrm{H}^{+} / \mathrm{K}^{+}$ATPase was a target of proton pump inhibitors, such as omeprazole. Omeprazole, when acid activated, will react with a large number of proteins, but generally acts mostly in the stomach, where acid activation is robust. Thus, it was not known whether the chloride transport channel (thought to be $\mathrm{ClC}-2$ ) was also affected by omeprazole. The ClC-2 channel in bilayers was found to be activated by acid activated omeprazole (11). This provided another potential way to activate the $\mathrm{ClC}-2$ channel, such as in the lung or in devices (see US patent 6,015,828).

\section{Search for drug binding sites}

The ClC-2 channel is known to be activated by a drug, lubiprostone, that is currently used in treatment of constipation $(14,15)$ and by a large variety of fatty acids, including arachidonic acid (13). In ongoing work, we have been searching for the binding region for lubiprostone and other fatty acids. Preliminary data (not shown) suggest that certain amino acids play a major role in activation of the channel by lubiprostone. The amino acid mutagenesis and chemical modification studies described above have provided information which can be compared with known X-ray and NMR structures of the $\mathrm{ClC}$ channels. For example, the crystal structure of parts of several $\mathrm{ClC}$ channels have appeared $(16,17)$, and NMR studies have described organized regions of the cytosolic C-terminus of the channel which cannot be crystallized (18). These structures, in conjunction with site directed mutagenesis studies provide a roadmap for understanding how various structures within the channel might lead to regulation of the channels.

\section{Discussion}

We have described our studies of reconstitution of potassium channels on solid and porous supports for pharmacological studies, reconstitution of the anthrax pore protein and $\alpha$-hemolysin with their respective membrane protein receptors, preparation of membranes with gramicidin which might be useful for fuel cells, and reconstitution of other membrane proteins, including ion pumps and channels. The work described in this chapter produced unique new materials with the ability to "sense" the environment and the same time send an electrical signal reporting changes in the chemical or physical environment. These devices can sense chemicals and toxins and even shrink and swell events or produce or transduce energy from biochemicals. Indeed, the present work contributes to a new field of engineering which can produce materials with unprecedented properties. In living cells, these ion channels and other chemi-osmotic transport proteins use electrochemical gradients formed by light and chemical substrates to produce and interconvert energy, mechanical work, electrical work, osmotic work, chemical work and heat. Using the described approaches, composite materials will be developed to do the same in the future. 
The approaches described are general. They can also be used for other channels. None of these techniques absolutely require that the ion channels be highly purified from cells and will work even if the ion channels represent a very small fraction of the total membrane protein. The reason for this is that ion channels have unique electrophysiological properties which allow them to be identified by ion selectivity, responses to drugs, unit conductance, voltage responses, and whether they act as single or double barreled channels. However, in some cases it is necessary to alter the source of ion channel protein. Thus, it is possible to increase the complement of ion channel proteins by over expression, to purify and even crystallize the proteins, or, as described above, prepare ion channel proteins with altered amino acid sequence. Purification of these proteins generally requires that the membranes in which they are embedded must be disrupted by detergents. Detergent disruption, subsequent purification and reconstitution into membrane vesicles disrupts the orientation of the membrane proteins into inside out and outside out configurations. This is in contrast to ion channels isolated from native membrane that are normally in one configuration, e.g. inside out. Nevertheless, it is possible to purify membrane vesicles containing a single ion channel in a single configuration by chromatography or free flow electrophoresis. These can then be reconstituted in a single configuration.

The techniques for insertion of ion channels (and other transporters) into porous supports are straightforward and generally applicable. The formation of the lipid bilayer and insertion of the proteins into the bilayer occur by self assembly. The procedure can be scaled from a few hundred square angstroms to square meters. It is also possible to expand upon the geometries of these devices, perhaps placing one type of protein on one side of a compartment, and another on the other side of a compartment, as occurs in living cells. Such studies can be understood within the context of the chemiosmotic theory (19), and can be best understood and driven in the future by that theory. Possible criticism of the approach is that the devices may not be sufficiently robust to function in harsh environments. However, as described in this chapter, some ion channels have been shown to be active at extremes of $\mathrm{pH}$ and at high temperatures.

\section{References}

[1] Stroffekova K., Kupert E. Y., Malinowska D. H., Cuppoletti J. (1998) Identification of the $\mathrm{pH}$ sensor and activation by chemical modification of the $\mathrm{ClC}-2 \mathrm{G} \mathrm{Cl}$ - channel. Am J Physiol 275: C1113-C1123.

[2] Sherry A. M., Stroffekova K., Knapp L. M., Kupert E. Y., Cuppoletti J., Malinowska D. H. (1997). Characterization of the human $\mathrm{pH}$ - and PKA-activated $\mathrm{ClC}^{-2} \mathrm{G}_{2 \alpha} \mathrm{Cl}^{-}$ channel. Am J Physiol 273: C384-C393.

[3] Dhoke M. A., Ladha P. J., Boerio F. J., Lessard L. B., Malinowska D. H., Cuppoletti J., Wieczorek D.S. (2005). Porous membranes for reconstitution of ion channels. Biochim Biophys Acta 1716: 117-125.

[4] Matsuno N., Murawsky M., Ridgeway J., Cuppoletti J. (2004). Solid support membranes for ion channel arrays and sensors: application to rapid screening of pharmacological compounds. Biochim Biophys Acta 1665: 184-190. 
[5] Cuppoletti J., Tewari K. P., Sherry A. M., Ferrante C. J., Malinowska D. H. (2004) Sites of protein kinase activation of the human $\mathrm{ClC}-2 \mathrm{Cl}^{-}$channel. J Biolll Chem 279: 1849-21856.

[6] Shenoy D. K., Barger W. R., Singh A., Panchal R. G., Misakian M., Stanford V. M., Kasianowicz J. J. (2005) Functional reconstitution of protein ion channels into planar polymerizable phospholipid membranes. Nano Lett 5: 1181-1185

[7] Wolfe J. T., Krantz B. A., Rainey G. J., Young J. A., Collier R. J. (2005) Whole-cell voltage clamp measurements of anthrax toxin pore current. J Biol Chem 280: 39417-39422.

[8] Pintschovius J., Fendler K., Bamberg E. (1999) Charge translocation by the $\mathrm{Na}^{+} / \mathrm{K}^{+}-$ ATPase investigated on solid supported membranes: cytoplasmic cation binding and release. Biophys J 76: 827-836.

[9] Pintschovius J., Fendler K. (1999) Charge translocation by the $\mathrm{Na}^{+} / \mathrm{K}^{+}-\mathrm{ATPase}$ investigated on solid supported membranes: rapid solution exchange with a new technique. Biophys J 76: 814-826.

[10] Cuppoletti, Birn S. S., Tewari K. P., Chakrabarti J., Malinowska D. H. (2008) Studies of Ion transport at extreme temperature. Experimental Biology, 2008.

[11] Cuppoletti J., Tewari K. P., Sherry A. M., Kupert E. Y., Malinowska D. H. (2001) ClC-2 $\mathrm{Cl}^{-}$channels in human lung epithelia: activation by arachidonic acid, amidation, and acid-activated omeprazole. Am J Physiol 281: C46-C54.

[12] Malinowska D. H., Kupert E. Y., Bahinski A., Sherry A. M., Cuppoletti J. (1995) Cloning, functional expression, and characterization of a PKA-activated gastric $\mathrm{Cl}^{-}$channel. Am J Physiol 268: C191-C200.

[13] Tewari K. P., Malinowska D. H., Sherry A. M., Cuppoletti J. (2000) PKA and arachidonic acid activation of human recombinant $\mathrm{ClC}-2$ chloride channels. Am J Physiol Cell Physiol 279: C40-C50.

[14] Cuppoletti J., Malinowska D. H., Tewari K. P., Li Q. J., Sherry A. M., Patchen M. L., Ueno R. (2004) SPI-0211 activates T84 cell chloride transport and recombinant human ClC-2 chloride currents. Am J Physiol Cell Physiol 287: C1173-C1183.

[15] Bao H. F., Liu L., Self J., Duke B. J., Ueno R. and Eaton D. C. (2008). A synthetic prostone activates apical chloride channels in A6 epithelial cells. Am J Physiol Gastrointest Liver Physiol 295: G234-G251.

[16] Dutzler R., Cambell E. B., Cadene M., Chalt B. T., MacKinnon R. (2002). X-ray structure of a ClC chloride channel at $3.0 \AA$ reveals the molecular basis of anion selectivity. Nature (Lond) 415: 287-294.

[17] Meyer S., Dutzler R. (2006). Crystal structure of the cytoplasmic domain of the chloride channel ClC-0. Structure 14: 299-307.

[18] Alioth S., Meyer S., Dutzler R., Pervushin K. (2007). The cytoplasmic domain of the chloride channel ClC-0: Structural and dynamic characterization of flexible regions. J Mol Biol 369: 1163-1169. 
[19] Mitchell P. (1978) Nobel Lecture: 8 David Keilin's respiratory chain concept and its chemiosmotic consequences.

http:/ / livingwaterusa.com/documents/mitchell-lecture\%20chemiosmosis.pdf 


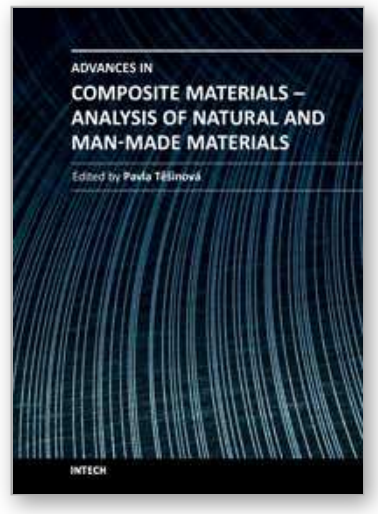

\author{
Advances in Composite Materials - Analysis of Natural and Man- \\ Made Materials \\ Edited by Dr. Pavla Tesinova
}

ISBN 978-953-307-449-8

Hard cover, 572 pages

Publisher InTech

Published online 09, September, 2011

Published in print edition September, 2011

Composites are made up of constituent materials with high engineering potential. This potential is wide as wide is the variation of materials and structure constructions when new updates are invented every day.

Technological advances in composite field are included in the equipment surrounding us daily; our lives are becoming safer, hand in hand with economical and ecological advantages. This book collects original studies concerning composite materials, their properties and testing from various points of view. Chapters are divided into groups according to their main aim. Material properties are described in innovative way either for standard components as glass, epoxy, carbon, etc. or biomaterials and natural sources materials as ramie, bone, wood, etc. Manufacturing processes are represented by moulding methods; lamination process includes monitoring during process. Innovative testing procedures are described in electrochemistry, pulse velocity, fracture toughness in macro-micro mechanical behaviour and more.

\title{
How to reference
}

In order to correctly reference this scholarly work, feel free to copy and paste the following:

John Cuppoletti and Danuta H. Malinowska (2011). Engineered Membranes and Transporters for Useful Devices, Advances in Composite Materials - Analysis of Natural and Man-Made Materials, Dr. Pavla Tesinova (Ed.), ISBN: 978-953-307-449-8, InTech, Available from: http://www.intechopen.com/books/advances-incomposite-materials-analysis-of-natural-and-man-made-materials/engineered-membranes-and-transportersfor-useful-devices

\section{INTECH}

open science | open minds

\section{InTech Europe}

University Campus STeP Ri

Slavka Krautzeka 83/A

51000 Rijeka, Croatia

Phone: +385 (51) 770447

Fax: +385 (51) 686166

www.intechopen.com

\section{InTech China}

Unit 405, Office Block, Hotel Equatorial Shanghai

No.65, Yan An Road (West), Shanghai, 200040, China

中国上海市延安西路65号上海国际贵都大饭店办公楼 405 单元

Phone: +86-21-62489820

Fax: $+86-21-62489821$ 
(C) 2011 The Author(s). Licensee IntechOpen. This chapter is distributed under the terms of the Creative Commons Attribution-NonCommercialShareAlike-3.0 License, which permits use, distribution and reproduction for non-commercial purposes, provided the original is properly cited and derivative works building on this content are distributed under the same license. 